\title{
Adaptations to feast and famine in different strains of the marine heterotrophic dinoflagellates Gyrodinium dominans and Oxyrrhis marina
}

\author{
Albert Calbet ${ }^{1, *}$, Stamatina Isari ${ }^{1}$, Rodrigo Andrés Martínez ${ }^{1}$, Enric Saiz ${ }^{1}$, \\ Susana Garrido², Janna Peters ${ }^{3}$, Rosa Maria Borrat ${ }^{1}$, Miquel Alcaraz ${ }^{1}$ \\ ${ }^{1}$ Institut de Ciències del Mar (CSIC), Passeig Marítim de la Barceloneta 37-49, 08003 Barcelona, Spain \\ ${ }^{2}$ Centre of Oceanography/Guia Marine Laboratory, Faculty of Sciences, University of Lisbon, \\ Avenida Nossa Senhora do Cabo 939, 2750-374 Cascais, Portugal \\ ${ }^{3}$ Institute for Hydrobiology and Fisheries Science, Hamburg University, Grosse Elbstrasse 133, 22767 Hamburg, Germany
}

\begin{abstract}
Marine planktonic organisms endure fluctuations in food abundance and quality during their life. The degree of resource variability in each specific environment may have forced adaptive survival responses on the organisms inhabiting them. We studied the adaptations to feast and famine of 2 strains of the heterotrophic dinoflagellates Gyrodinium dominans (GYR-DK from Denmark; GYR-BCN from Barcelona) and Oxyrrhis marina (OXY-BCN from Barcelona; OXY-CRB from the Caribbean). Overall, the OXY strains showed contrasting results in terms of feeding, metabolism, and biochemical composition, whereas both GYR strains presented similar responses to the variables measured. OXY-BCN exhibited higher maximum ingestion rates, better capacity to exploit a pulse of food, higher carbon assimilation efficiency and lipid storage capacity, and longer survival time to starvation. When feeding on a fatty acid-rich alga (Rhodomonas salina, RHO), OXYBCN displayed very high (75\%) gross growth efficiencies (GGE), but showed no growth when conditioned to one that was more fatty acid deficient (Dunaliella tertiolecta, DUN). In contrast, both GYR strains had higher GGE when feeding on DUN (>50\%) compared to a diet of RHO (16 to $22 \%$ ). OXY-CRB showed low GGE $(<20 \%)$, despite feeding actively on both prey. All strains maintained their carbon and nitrogen stoichiometry after $5 \mathrm{~d}$ starvation, but lost some fatty acids, especially OXY. Additionally, when starving, respiration rates decreased by $70 \%$ in OXY-BCN, $50 \%$ in GYRDK, and by $25 \%$ in OXY-CRB. Our results demonstrate that OXY-BCN is a more opportunistic organism, perfectly adapted to heterogeneous or unstable environments; although it requires a suitable biochemical composition in its prey. On the other hand, GYR seems better conditioned to more stable habitats, such as coastal and open waters. This study also stresses the phenotypic differences between strains (especially of OXY) originating from different ecosystems.
\end{abstract}

KEY WORDS: Gyrodinium dominans - Oxyrrhis marina - Starvation - Strain · Food quality · Feeding $\cdot$ Growth $\cdot$ Respiration $\cdot$ Fatty acids

Resale or republication not permitted without written consent of the publisher

\section{INTRODUCTION}

Marine planktonic habitats are highly patchy in resources both in space and time (Haury et al. 1978, Mackas et al. 1985). This heterogeneity, observed even at a scale of significance for protozoans (Meyer-
Reil et al. 1979, Fenchel 1982), is experienced by organisms as fluctuations of food over time, referred to as a 'feast and famine' (Koch 1971, Fenchel 1982, 1989, Jakobsen \& Hansen 1997). Such fluctuations may define the habitat of an organism and condition its adaptive strategies. For instance, organisms with 
limited migrating capacity, such as protozoans, may be directed towards the maximum exploitation of the available resources (when abundant) or/and to an improved resistance to starvation. The first adaptive strategy is usually accomplished by enhanced feeding responses, combined with fast digestion times, or by the ability to store food in the body (Fenchel 1989, Menden-Deuer et al. 2005, Meunier et al. 2012a,b). The second predominantly leads to a decrease in metabolic rates, cyst formation, and the efficient use of reserves (Fenchel 1982, 1989, Hansen 1992, Menden-Deuer et al. 2005, Meunier et al. 2012a,b). However, particular adaptations towards the search for new resources and habitats have also been reported (Tiselius et al. 1993). These adaptations include the division of the organism and the increase of motility when food is lacking as a means of increasing the probability of encountering a new patch of food (Fenchel 1989, Jakobsen \& Hansen 1997). Not only is the maximization of survival important when facing periods of resource fluctuation, but also the ability to rapidly resume growth; although this is usually accomplished at the expense of preserving the entire metabolic machinery which has an energetic cost (Fenchel 1989). Finally, it is evident that the heterogeneity in resources through time and space extends to the quality of food. Changes such as the natural seasonal succession of species or the swarming of autotrophic and heterotrophic prey in patches are also experienced by the grazers as fluctuations in the nutrient quality of their prey.

It is difficult to define what a poor diet is for protozoans, and to identify what biochemical compounds are essential. On the other hand, much work has been done with copepods, relating fatty acid (FA) composition to egg production and hatching success. Heterotrophic dinoflagellates have been shown to be able to upgrade the quality of certain nanoflagellate species lacking essential FA (such as eicosapentaenoic acid [EPA], and docosahexaenoic acid [DHA]) to higher trophic levels (Klein Breteler et al. 1999, 2004, Veloza et al. 2006, Chu et al. 2008b, Lund et al. 2008). The metabolic processes involved in this upgrading by heterotrophic dinoflagellates seems not to rely on the elongation and desaturation of dietary precursors, but rather on the production of long-chain essential FA (i.e. DHA and EPA) de novo (Lund et al. 2008). However, all biochemical processes have metabolic costs; therefore, it makes sense to assume that consumption of 'poor quality' (low in, or lacking certain FA and sterols) food will have consequences on the net growth of the grazers, and in the way these lipids are used during starvation.
In the present study, we examine the adaptive strategies of heterotrophic marine dinoflagellates to feast and famine conditions. We focus on the diverse responses that different species show when faced with food resources of different quality and availability, as well as major constraints affecting the survival of the individual and its capability to reproduce under suboptimal conditions. We expect the responses (in aspects such as feeding ability, lipid reserves, growth rates, and resistance to starvation) to be markedly distinct as a result of the adaptive characteristics that each species has developed for thriving in their particular habitat.

To conduct our study we chose the dinoflagellates Gyrodinium dominans and Oxyrrhis marina. Both species are quite cosmopolitan, thriving in a wide range of climatic conditions (Hansen 1992, Nakamura et al. 1995, Lowe et al. 2011, Watts et al. 2011). However, they clearly differ in their habitat: G. dominans is a typical coastal species, at times found in open waters (Hansen 1992, Nakamura et al. 1995, Kim \& Jeong 2004, Jeong et al. 2011), whereas O. marina mostly inhabits intertidal pools (Droop 1953, Jonsson 1994, Johnson 2000), salt marshes, and embayments (Begun et al. 2004), is rarely pelagic, and is seldom found in open oceanic waters (Lowe et al. 2011, Watts et al. 2011). The different environments that these species occupy have contrasting biological, physical and chemical properties, which have likely conditioned their adaptive ecological and physiological strategies. For instance, it is expected that $O$. marina would experience more environmentally extreme conditions in their habitat (e.g. wider oscillations in temperature, salinity, food availability, and oxygen concentration; Metaxas \& Scheibling 1993, Martins et al. 2007) in comparison with G. dominans. To strengthen the robustness of our comparison, we chose 2 strains of $G$. dominans and $O$. marina obtained at different locations, since working with a single strain is not sufficient to fully understand the behavior and physiological traits of the protist species (Nakamura et al. 1995, Adolf et al. 2007, Calbet et al. 2011, Lowe et al. 2011). Indeed, in the case of O. marina, it is evident that high levels of genetic diversity occur within the current O. marina morphospecies (Cavalier-Smith \& Chao 2004, Lowe et al. 2005, 2010, 2011), probably resulting in different traits being exhibited between different populations. As prey, we used 2 similarly sized algae, Rhodomonas salina and Dunaliella tertiolecta, that differ in their FA profiles (Klein Breteler et al. 1999, Veloza et al. 2006, Chu et al. 2008b, Lund et al. 2008, this study), but have similar C:N ratios when grown in an excess of nutrients (Brutemark et al. 2009). 
We propose 2 hypotheses in this study, based on the different responses of the 2 species when faced with variability in the supply and quality of food. Firstly, given the environmental variability associated with the habitats of Oxyrrhis marina, we expect that this species would possess adaptations to take the maximum advantage of an intermittent supply of food, and therefore would also be able to undergo longer periods of starvation than Gyrodinium dominans. The mechanisms underlying these contrasting performances may involve differences in vital processes such as prey uptake rates, storage capability, and/or metabolic traits. Secondly, since a priori both species should have similar nutritional requirements regarding the biochemical composition of prey, we hypothesize that the growth rates of both species should be lower when feeding on Dunaliella tertiolecta (poor in some specific FAs), compared with Rhodomonas salina.

We evaluated both hypotheses by comparing the responses in feeding and growth rates, FA contents, and respiratory activity to different food conditions (i.e. continuous supply, discrete or pulsed supply, starvation, different nutritional value of the prey) in all species strains.

\section{MATERIALS AND METHODS}

\section{Cultures}

We conducted our study using different strains of dinoflagellates, originating from very different ecosystems, to provide a range of variability of the species responses. Gyrodinium dominans DK (GYRDK) was isolated by H. H. Jakobsen (unpubl.) in 1996 from the northern part of Øresund (Denmark; Hansen \& Daugbjerg 2004); G. dominans BCN (GYR-BCN) was isolated by A. Calbet near Barcelona (NW Medi- terranean) in February 2011 (A. Calbet pers. obs.). The strain Oxyrrhis marina BCN (OXY-BCN) was also isolated by A. Calbet off the Barcelona coast in 1996 (A. Calbet pers. obs.), whereas O. marina CRB (OXYCRB) originates from the Great Salt Pond, St. Maarten, Caribbean, and was purchased from the SCCAP (Denmark; code SCCAP-0592). All strains were kept in autoclaved $0.2 \mu \mathrm{m}$ filtered seawater that contained trace amounts of EDTA and trace metals $\left(0.003 \mathrm{ml} \mathrm{l}^{-1}\right.$ of $\mathrm{f} / 2$ metal stock solution; Guillard 1975$)$, at $18^{\circ} \mathrm{C}$, $38 \mathrm{psu}$, under dim light, and unless otherwise indicated for each particular experiment, fed on Rhodomonas salina. The strains that originated from areas with different temperature and salinity from our standard laboratory conditions $\left(18^{\circ} \mathrm{C}, 38 \mathrm{psu}\right)$ were gradually adjusted during weeks or months, depending on the requirements of each species.

Regarding the prey, Dunaliella tertiolecta (DUN; ESD 6.2 to $6.5 \mu \mathrm{m}$ ) was purchased from the National Center for Marine Algae and Microbiota (NCMA; Boothbay, Maine) in 2008 and it has unknown origin. Rhodomonas salina (RHO; ESD 6.3 to $6.5 \mu \mathrm{m}$ ) strain K-0294 was originally obtained from the Scandinavian Culture Collection of Algae and Protozoa at the University of Copenhagen and it has been kept cultured in the laboratory at ICM-CSIC for several years. All prey species were kept in f/2 medium (Guillard 1975), under exponential growth conditions, at $18^{\circ} \mathrm{C}, 38 \mathrm{psu}, 100-200 \mu \mathrm{E} \mathrm{m} \mathrm{m}^{-2} \mathrm{~s}^{-1}$, and a 12:12 h light:dark cycle. In Table 1 we present a synoptic summary of the different experiments we did with each strain, as described in detail below.

\section{Functional responses to food concentration}

To obtain the basic parameters (e.g. maximum ingestion rates, feeding saturation concentrations)

Table 1. Experiments conducted with 2 strains of Oxyrrhis marina (OXY-BCN and OXY-CRB) and Gyrodinium dominans (GYR-DK and GYR-BCN), feeding on Rhodomonas salina (RHO) and Dunaliella tertiolecta (DUN). For further details see

'Materials and methods'. FSW $=$ filtered seawater. The $+/-$ symbol indicates experiments were or were not conducted

\begin{tabular}{|c|c|c|c|c|c|}
\hline & Type of food & OXY-BCN & OXY-CRB & GYR-DK & GYR-BCN \\
\hline \multirow[t]{2}{*}{ Functional responses to food concentration } & RHO & + & + & + & + \\
\hline & DUN & + & - & + & - \\
\hline Short-term feeding behavior & RHO & + & - & + & - \\
\hline Starvation effects on survival and biovolume & RHO & + & - & + & - \\
\hline \multirow[t]{2}{*}{ Growth and gross growth efficiency } & RHO & + & + & + & + \\
\hline & DUN & + & + & + & + \\
\hline \multirow[t]{2}{*}{ Starvation effects on biochemical composition } & $\mathrm{RHO}$ & + & + & + & + \\
\hline & DUN & + & + & + & + \\
\hline \multirow[t]{2}{*}{ Respiration } & RHO & + & + & + & - \\
\hline & FSW & + & + & + & - \\
\hline
\end{tabular}


needed to design the remainder of the experiments, we obtained the feeding and growth functional response to food concentration for GYR-DK and OXY-BCN using RHO and DUN as prey. The experiments with GYR-BCN and OXY-CRB were conducted only with RHO. The grazers were kept for $4 \mathrm{~d}$ in two $4 \mathrm{l}$ Pyrex culture flasks and fed either RHO or DUN ad libitum. The day before the experiment, we calculated the prey concentration required in order to be mostly depleted after $24 \mathrm{~h}$. To carry out the functional response experiments, we prepared a concentrated mixed suspension with a predator:prey proportion of ca. 1:250 and 1:600 for GYR and OXY, respectively, starting with 500000 prey $\mathrm{ml}^{-1}$. These concentrations were chosen in light of previous trials to allow for a $<30 \%$ depletion of prey after the incubation time $(24 \mathrm{~h})$. In parallel, we set suspensions containing only the prey at the same concentration as the mixed suspensions (grazer + prey), to serve as controls for the growth of the algae. The suspensions were consecutively diluted with filtered seawater in order to obtain a gradient of 7 consecutively halved levels of grazers and prey. To compensate for microzooplankton excretion effects on the algae, $10 \mathrm{ml} \mathrm{f} / 2$ per liter of suspension were added (i.e. final nutrient concentration equivalent to $f / 200$ ). Once the suspensions were prepared, we filled 4 experimental (grazer + prey) and 3 control (only prey) $75 \mathrm{ml}$ polyethylene culture flasks, taking special care to fill them gradually in 3 to 4 steps, gently mixing the suspension between fillings. For each food level, one flask of both experimental and control treatments were used as initial samples to verify initial concentrations of prey and grazer with a Multisizer III particle counter. The remaining flasks were placed on a plankton wheel $(0.2 \mathrm{rpm})$, inside a temperature-controlled room under the temperature and light conditions described above. After ca. $24 \mathrm{~h}$ the experiment was taken down and the concentration of prey and grazers measured. To calculate grazing rates and average prey concentrations we used Frost's (1972) equations; per capita values were calculated using the average concentration of grazers in each replicate (Heinbokel 1978). Ingestion rates were fitted to a Type II Holling functional response by minimizing the sum of squares.

\section{Short-term feeding response to a pulse of food}

To evaluate the response of OXY and GYR to a discrete food supply we prepared 2 cultures of GYR-DK and OXY-BCN, fed ad libitum with RHO. When the grazers reached a suitable concentration, the cultures were not re-supplied with prey for $2 \mathrm{~d}$, allowing the grazers to entirely clear all food. In the last $24 \mathrm{~h}$, food was completely absent and therefore the grazers were starved for at least $24 \mathrm{~h}$. After this period of time the prey inside the organism were completely digested (see below). We then prepared duplicated 21 Pyrex bottles with both dinoflagellate species at a concentration of ca. 2000 cells ml $^{-1}$. At that time, we added a known concentration of RHO (200 000 RHO $\mathrm{ml}^{-1}$ ) and used a Multisizer III particle counter to monitor the abundance and cell volume of grazers and prey at intervals of 1 to $2 \mathrm{~min}$ for the first $90 \mathrm{~min}$, spacing out the periods of sampling up to $10 \mathrm{~h}$ incubation. Algal growth rates were estimated in duplicate controls (without grazers) at hourly intervals. The bottles were homogenized carefully prior to each sampling.

\section{Starvation}

To assess the capability of OXY and GYR to withstand starvation, we supplied OXY-BCN and GYRDK with ca. 100000 RHO ml-1 in a single addition and observed the temporal changes in cell abundance of both predator and prey for $12 \mathrm{~d}$. At the end of this period, we supplied a similar concentration of food again, and monitored the decline of prey and the response of grazers for 7 additional days. This second input of food allowed us to establish whether the grazer community could recover, and how fast a possible recovery would be. The experiments were run in duplicate 21 Pyrex bottles under the same conditions as described before.

\section{Effects of the diet on growth and gross growth efficiency}

To assess balanced growth and gross growth efficiencies (GGE), we kept all the strains of dinoflagellates under satiating food concentration (according to the results of the previous functional response experiments) of either RHO or DUN for $3 \mathrm{~d}$. The acclimation took place in 11 Pyrex glass culture flasks at 200000 prey $\mathrm{ml}^{-1}$ for GYR and 600000 prey $\mathrm{ml}^{-1}$ for $\mathrm{OXY}$, adjusting the concentrations every day and not allowing a decay of food below feeding saturating conditions. On Day 4, we again adjusted the concentrations and set the GGE experiment in $75 \mathrm{ml}$ polyethylene culture flasks. The treatments consisted of 4 
to 5 experimental bottles with each of the combinations of grazers and prey (Table 1), and 3 to 4 controls without grazers. For each treatment we used one bottle as an initial sample. Other procedures were similar to those described for the functional response experiments.

\section{Changes in biochemical composition}

To establish whether the biochemical composition of the different dinoflagellate strains reflected that of their prey, and for how long, we analyzed the carbon (C) and nitrogen (N) contents and the lipid profile of the target heterotrophic dinoflagellates (Table 1) during the digestion process, and compared it with that of their prey. For that purpose, we determined $\mathrm{C}: \mathrm{N}$ ratio and FA content of the dinoflagellates at 3 distinct stages of the culture development. Stage I: when food had been consumed but the digestion was still in process and the predator's body was occupied by prey items (checked both visually and using a Multisizer III particle counter). Stage II: after $2 \mathrm{~d}$ of food depletion, when no prey could be observed inside the predator. Stage III: $3 \mathrm{~d}$ after Stage $\mathrm{II}_{\text {; }}$ i.e. after $5 \mathrm{~d}$ of food deprivation. In order to accomplish this, all strains were kept growing in 21 Pyrex glass culture flasks under high concentrations of RHO and DUN (ca. 500000 cells ml $^{-1}$ for OXY and ca. 150000 cells $\mathrm{ml}^{-1}$ for GYR) for $3 \mathrm{~d}$ (the algae concentrations adjusted daily). At each of the previously indicated stages pseudo-duplicate and triplicate aliquots for C:N and FA analyses, respectively, were filtered on pre-combusted (also pre-weighted when used for FA estimation) Whatman GF/C filters. Samples were also taken from the prey (RHO and DUN) batch cultures, growing exponentially in our standard laboratory conditions, for biochemical analysis. After filtration, filters for $\mathrm{C}$ and $\mathrm{N}$ analysis were dried at $60^{\circ} \mathrm{C}$ for $24 \mathrm{~h}$, while those for FA analysis were frozen, preserved at $-80^{\circ} \mathrm{C}$, and lyophilized before analysis.

We determined $\mathrm{C}$ and $\mathrm{N}$ contents with a Carlo-Elba CHN analyzer. Lipid extraction and conversion of acyl groups into methyl ester derivatives (FAMES) was performed as described in Peters et al. (2006), using modified protocols of Folch et al. (1957) and Kattner \& Fricke (1986). FAMES and fatty alcohols were separated by gas chromatography, detected by flame ionisation and identified by comparing retention times with those derived from standards of known composition. Only those compounds that reached $>2 \%$ of total FA and fatty alcohols in any of the samples were considered for the calculation of total FA content. Further data analysis focused only on the 10 most important FA (defined as those that reached a contribution of at least $5 \%$ of the total FA of one sample within the whole data set). The FA were quantified using the FA 23:0 as internal standard, added prior to the lipid extraction.

\section{Respiratory $\mathrm{C}$ losses and responses to starvation}

We evaluated the respiration rates of 3 of the 4 dinoflagellate strains (unfortunately, we were unable to obtain data for GYR-BCN due to problems with the oxygen sensors). The respiration activity of the dinoflagellates was measured in the presence and in absence of food (RHO); to account for changes in oxygen concentration due to the presence of prey, 2 additional control treatments (i.e. prey alone, and $0.2 \mu \mathrm{m}$ filtered seawater) were set. All incubations were conducted in triplicate $130 \mathrm{ml}$ Pyrex glass bottles, in darkness, at $18^{\circ} \mathrm{C}$, and lasted for $24 \mathrm{~h}$. Previously, the dinoflagellates had been gently concentrated by gravity filtration through a $3 \mu \mathrm{m}$ polycarbonate filter to remove excess bacteria and detritus, re-suspended in filtered seawater, and pre-conditioned (without food) for a period of $24 \mathrm{~h}$. Dinoflagellate density in the incubations was ca. 3000 ind. $\mathrm{ml}^{-1}$. In the treatments with food, RHO was added at a concentration of $\sim 100000$ cells $\mathrm{ml}^{-1}$ to ensure saturated food conditions. Oxygen concentration was monitored using optical oxygen sensors (Oxygen Dipping Probe DP-PSt3, PreSens), at a measuring frequency of $15 \mathrm{~min}$, with a setup similar to that described in Almeda et al. (2011).

In the case of both the prey and the grazers incubated alone in filtered seawater, oxygen consumption rates ( $\mu \mathrm{mol} \mathrm{O}_{2} \mathrm{~h}^{-1}$ ) were estimated as the slopes of the linear regression equations relating incubation time and dissolved oxygen concentration, after correcting for any changes in dissolved $\mathrm{O}_{2}$ observed in the control bottles with only filtered seawater. Cellspecific respiration rates $\left(\mu \mathrm{mol} \mathrm{O}_{2} \mathrm{~h}^{-1}\right.$ cell $^{-1}$ ) were then calculated by dividing the experimental oxygen consumption rates on a per bottle basis by the average cell concentration during the incubation.

For the grazers incubated with prey, the oxygen consumption on a per bottle basis was a result of the combined respiration of the grazers (heterotrophic dinoflagellates) and the prey (RHO). For this reason, before calculating the actual per capita consumption by the dinoflagellates we had to subtract the decay 
in oxygen concentration due to the presence of RHO. To do so, we estimated the average RHO concentration in the mixed suspension bottles at each oxygen-measurement time interval using Frost's equations (Frost 1972). Then, we applied the cell-specific RHO respiration rates (from the incubation with single RHO suspension) to the actual RHO concentration in the mixed suspension, estimated at each measuring time interval. Oxygen consumption due to the grazers in the mixed suspensions was estimated from the slope of changes in dissolved $\mathrm{O}_{2}$ through time after subtracting the $\mathrm{O}_{2}$ consumption of RHO as described above. Finally, the per capita respiration rate of the dinoflagellates in the presence of food was calculated taking into account the average number of dinoflagellates incubated.

\section{RESULTS}

\section{Functional responses to food concentration}

The clearance and ingestion rates of 2 strains of GYR and OXY on RHO are presented in Fig. 1. The maximum clearance of OXY strains $\left(4 \mu \mathrm{cell}^{-1} \mathrm{~d}^{-1}\right)$ was ca. 4 times higher than that of GYR. Regarding OXY strains, OXY-BCN displayed higher maximum clearance rates (Fig. 1A,B). Both GYR strains and OXY-CRB ingested RHO at a similar maximum rate, although OXY-CRB reached saturation faster $(\mathrm{p}<$ 0.05 , extra sum-of-squares $F$ test; Table 2 , Fig. $1 C, D)$. On the other hand, OXY-BCN ingested RHO at higher maximum rates (ca. 3 times higher than the other grazers; $\mathrm{p}<$ 0.01). Once converted to $C$, the specific ingestion rates followed similar patterns to those calculated on a cell basis, with OXY$\mathrm{BCN}$ having the highest specific ingestion rates (Table 2). When food was provided ad libitum, the daily rations (\% body $\mathrm{C}$ ingested per day) of all strains of dinoflagellates were $>300 \%$ (Fig. 1E,F,
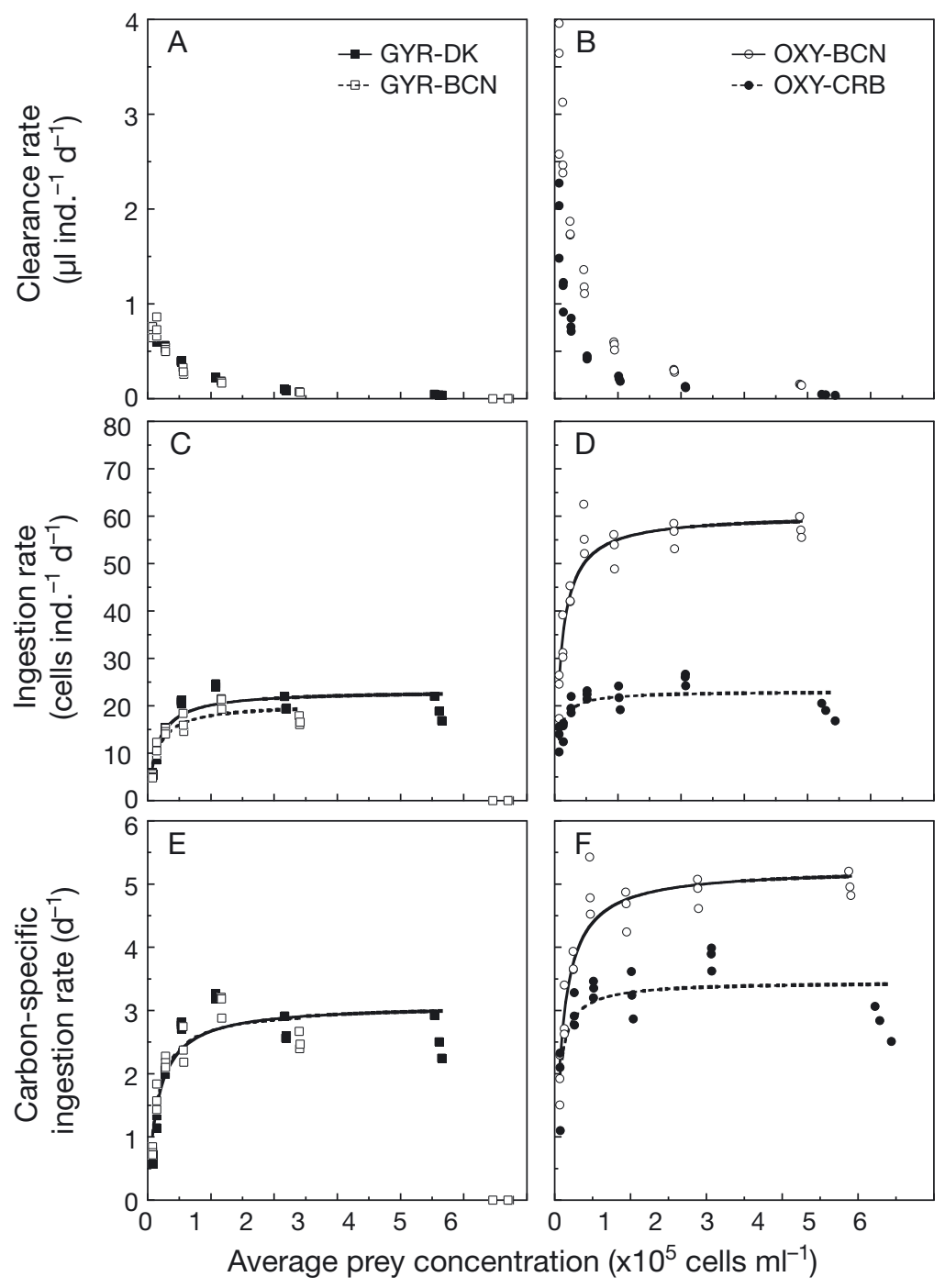

Fig. 1. $(\mathrm{A}, \mathrm{B})$ Clearance rates, $(\mathrm{C}, \mathrm{D})$ ingestion rates, and $(\mathrm{E}, \mathrm{F})$ carbon-specific ingestion rates of Gyrodinium dominans (GYR-DK and GYR-BCN; left panels), and Oxyrrhis marina (OXY-BCN and OXY-CRB; right panels) as a function of Rhodomonas salina concentration. Parameters of the fitted equations are presented in Table 2. Carbon-specific ingestion rates were computed based on the standard biomass of an unfed organism, as shown for Day 2 in Table 5. Note GYR-BCN fit did not use the value at the highest food concentration

Table 2. Gyrodinium dominans (GYR-DK and GYR-BCN) and Oxyrrhis marina (OXY-BCN and OXY-CRB) feeding on Rhodomonas salina. Model fit parameters for the equation $I=I_{\max } \times \mathrm{p} /(\mathrm{Km}+\mathrm{p})$ corresponding to both cell-based and carbon-based ingestion rates shown in Fig. 1. $I=$ ingestion rates, $I_{\max }=$ maximum ingestion rates, $\mathrm{p}=$ prey concentration, $\mathrm{Km}=$ the half saturation constant. Values in parentheses are the error of the estimate

\begin{tabular}{|c|c|c|c|c|c|c|}
\hline \multirow{2}{*}{ Grazer } & \multicolumn{3}{|c|}{ Cell-based } & \multicolumn{2}{|c|}{ Carbon-based } & \multirow[b]{2}{*}{$\mathrm{r}^{2}$} \\
\hline & $I_{\max }$ & $\mathrm{Km}$ & $r^{2}$ & $I_{\max }$ & $\mathrm{Km}$ & \\
\hline GYR-DK & $23.2(1.22)$ & $15347(3614)$ & 0.81 & $3.09(0.17)$ & 15765 (3788) & 0.81 \\
\hline GYR-BCN & $20.5(1.07)$ & 14086 (2921) & 0.85 & $3.05(0.16)$ & $14086(2920)$ & 0.85 \\
\hline OXY-BCN & $60.4(1.75)$ & 9576 (1333) & 0.89 & $5.25(0.15)$ & 9814 (1372) & 0.89 \\
\hline OXY-CRB & $23.2(1.09)$ & 5155 (1765) & 0.57 & $3.46(0.16)$ & 5155 (1764) & 0.57 \\
\hline
\end{tabular}



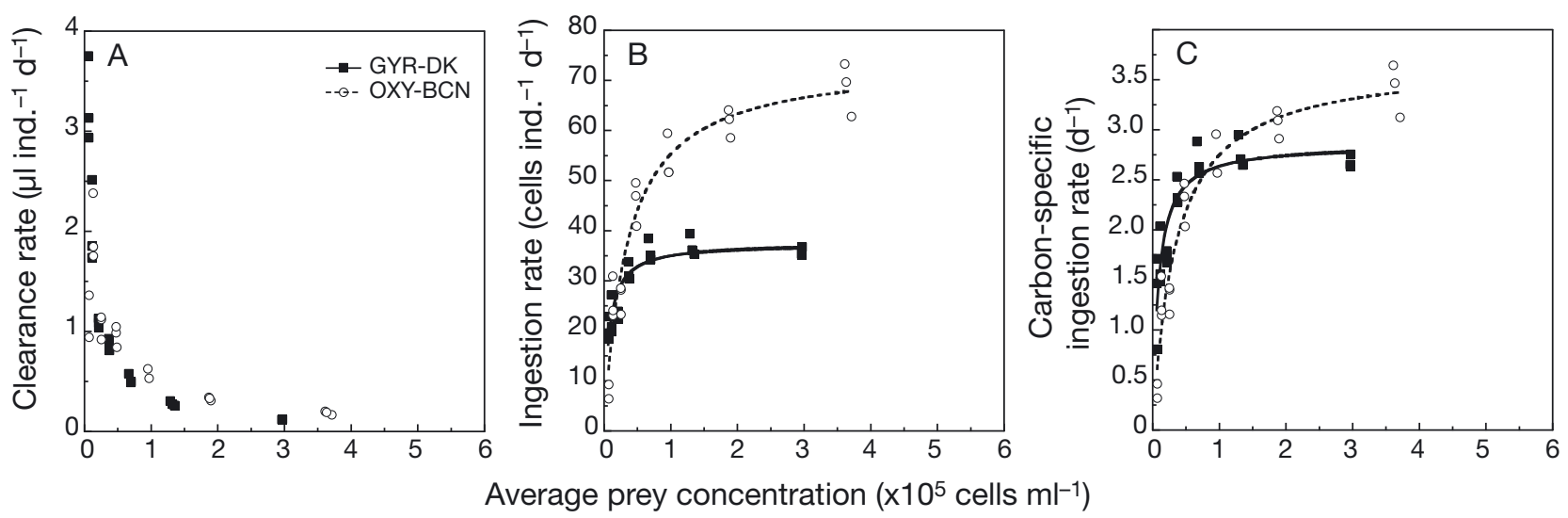

Fig. 2. (A) Clearance rates, (B) ingestion rates, and (C) carbon-specific ingestion rates of Gyrodinium dominans (GYR-DK) and Oxyrrhis marina (OXY-BCN) as a function of Dunaliella tertiolecta concentration. Parameters of the fitted equations are presented in Table 3

Table 2). In all cases there was no threshold for clearance at lower prey concentrations. GYR-BCN ceased ingestion rates when food concentration was too high (Fig. 1C,E).

Under a DUN diet, GYR-DK showed higher clearance rates at low food concentrations than OXY-BCN (Fig. 2A, Table 3). OXY-BCN took longer to saturate feeding, but reached twice the maximum ingestion rates of GYR-DK ( $p<0.01)$. These differences were less for carbon-specific ingestion rates, although still significant ( $\mathrm{p}<0.01$; Fig. $2 \mathrm{C}$ ). When compared with the rates of the strains fed $\mathrm{RHO}$, only OXY-BCN showed relevant and significant differences, with lower maximum ingestion rates when fed DUN (Table 3; p < 0.01, extra sum-of-squares F test; Motulsky \& Christopoulos 2003).

\section{Short-term feeding behavior and body plasticity}

Only GYR-DK and OXY-BCN were targeted to examine the short-term response to a pulse of food. Starting from similar concentrations of grazers, OXY-
BCN severely impacted the population of prey $(50 \%$ reduction) by the end of the experiment (ca. $10 \mathrm{~h}$ ), whereas GYR-DK presented a modest reduction of $10 \%$ of the initial prey concentration (Fig. 3A). The increase in cell volume resulting from the accumulation of prey into the grazer was also different between species. OXY-BCN multiplied their initial volume 4-fold, whereas GYR-DK only increased 1.5-fold (Fig. 3B). The dynamics of this process followed an asymptotic trend for OXY-BCN, and a more linear pattern for GYR-DK. Moreover, GYR-DK accumulated the prey into one extremity of the cell, whereas OXY filled its entire body with prey (authors' pers. obs.).

The calculated potential ingestion rates integrating short periods of time revealed that both GYRDK and OXY-BCN modified their feeding behavior during the incubation (Fig. 4). The initial feeding rates were very high (35 and 8 cells ind ${ }^{-1} \mathrm{~h}^{-1}$ for OXY-BCN and GYR-DK, respectively), but there were quickly decreased, and after $100 \mathrm{~min}$ of incubation both ingestion rates seemed to stabilize at ca. 4 cells $\mathrm{h}^{-1}$ per OXY-BCN and ca. 2 cells $\mathrm{h}^{-1}$ ingested per GYR-DK (Fig. 4).
Table 3. Gyrodinium dominans (GYR-DK) and Oxyrrhis marina (OXY-BCN) feeding on Dunaliella tertiolecta (DUN). Model fit parameters for the equation $I=$ $I_{\max } \times \mathrm{p} /(\mathrm{Km}+\mathrm{p})$ corresponding to both cell-based and carbon-based ingestion rates shown in Fig. 2. See Table 2 for details

\begin{tabular}{|c|c|c|c|c|c|c|}
\hline \multirow{2}{*}{ Grazer } & \multicolumn{3}{|c|}{ Cell-based } & \multicolumn{2}{|c|}{ Carbon- } & \multirow[b]{2}{*}{$r^{2}$} \\
\hline & $I_{\max }$ & $\mathrm{Km}$ & $r^{2}$ & $I_{\max }$ & $\mathrm{Km}$ & \\
\hline GYR-DK & $37.5(1.27)$ & 7145 (1203) & 0.81 & $2.86(0.11)$ & 8388 (1498) & 0.81 \\
\hline OXY-BCN & $74.1(2.97)$ & $34120(4666)$ & 0.94 & $3.69(0.15)$ & 34120 (4667) & 0.94 \\
\hline
\end{tabular}

\section{Starvation and recovery response}

When GYR-DK and OXY-BCN were exposed to a pulse of RHO, both species initially increased their abundance (taking advantage of the available prey during the first $4 \mathrm{~d}$ ), and then either 

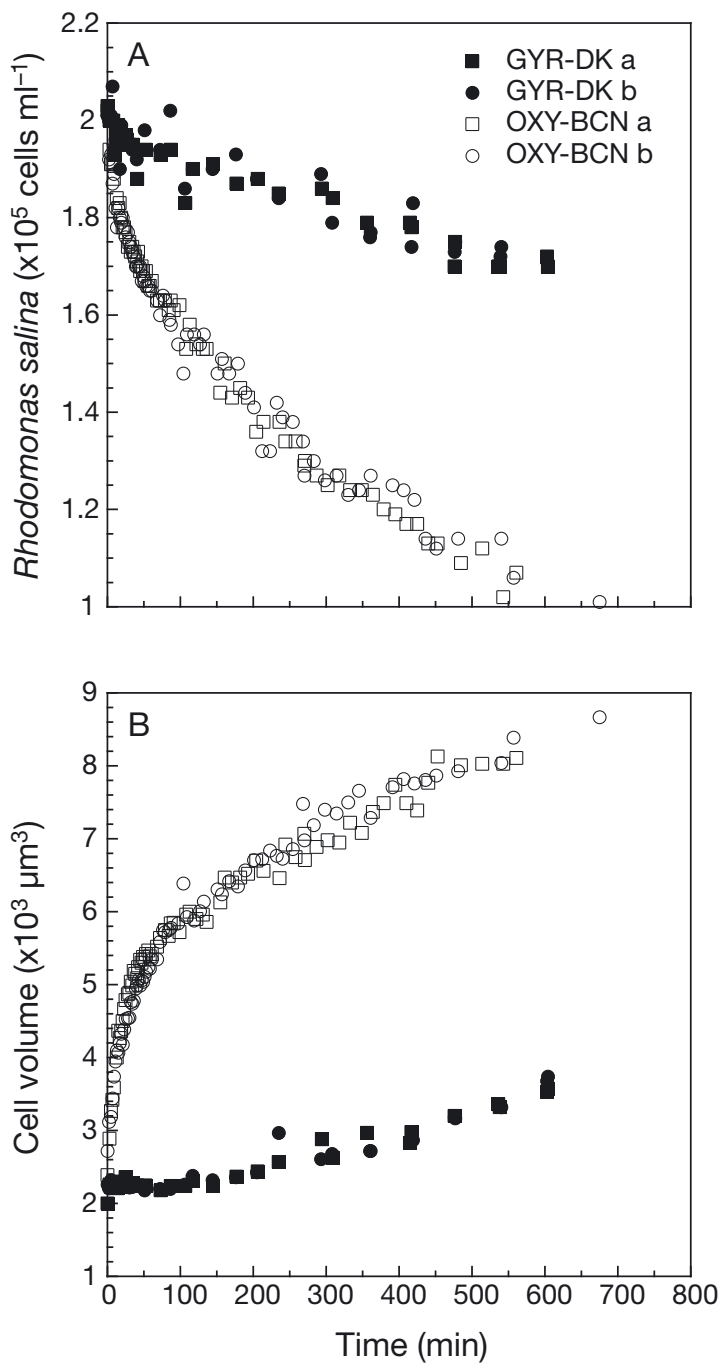

Fig. 3. Response of starved Oxyrrhis marina (OXY-BCN) and Gyrodinium dominans (GYR-DK) to a discrete supply of food Rhodomonas salina (RHO). (A) Diminution of RHO in replicated bottles $(a, b)$ at discrete time intervals. (B) Increase in cellular volume of OXY-BCN and GYR-DK at the same time intervals resulting from feeding

decreased abundance (cell mortality in the case of GYR-DK), or remained quite stable (OXY-BCN) for the following $8 \mathrm{~d}$ when the new pulse of food was supplied (Fig. 5). It is noteworthy that OXY-BCN was able to continue duplicating for $2 \mathrm{~d}$ after all available food was consumed, whereas GYR-DK decreased its population immediately after food exhaustion. Mortality rates for the period of food deprivation were low for OXY-BCN ( $2 \%$ of daily decrease), and of the order of $10 \%$ of daily decrease in the population for GYR-DK. After the second pulse of food was supplied both populations recovered, but a quicker response was observed in OXY-BCN.

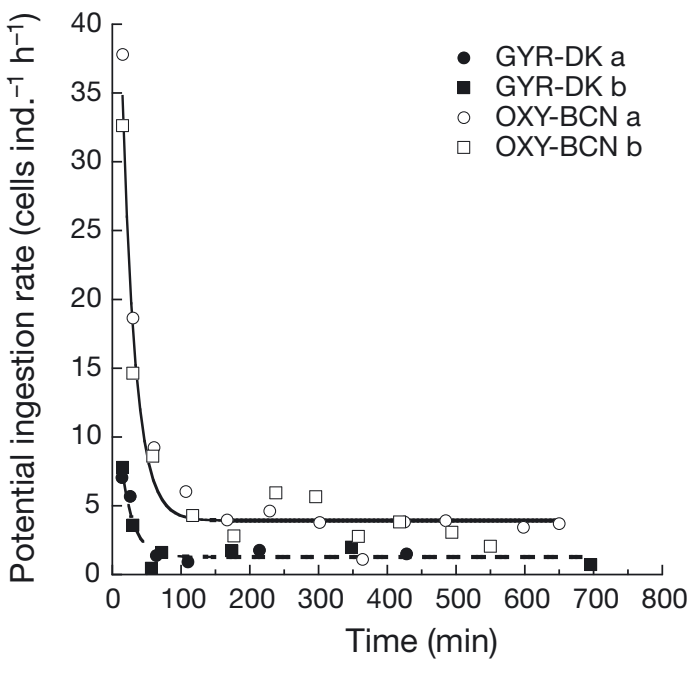

Fig. 4. Calculated potential ingestion rates integrating short periods of time. Data for calculations from Fig. 3. Replicated bottles are indicated as a,b

\section{Effects of diet on feeding, growth and GGE}

After acclimating for $3 \mathrm{~d}$ on a diet of either RHO or DUN (reaching balanced growth rates; data not shown), the growth and grazing rates of the different strains of dinoflagellates differed significantly (ANOVA, p $<0.01$ for both variables; Table 4 ). The 4 strains showed similar per cell ingestion rates, except for OXY-CRB, which displayed much higher rates when feeding on DUN than the rest of the grazers feeding on any prey, and when feeding on RHO than GYR-DK on both prey (ANOVA, Tukey-Kramer post hoc test, $\mathrm{p}<0.05$ ). These high ingestion values were also observed during the preconditioning process (data not shown). Cell-based growth rates ranged minimally for GYR-DK feeding on both diets $(0.17$ to $0.23 \mathrm{~d}^{-1}$ ), but were twice as high for GYR-BCN feeding on DUN than on RHO (although differences were not statistically significant at the 0.05 significance level, ANOVA, Tukey-Kramer post hoc test). The highest differences were found for the strains of OXY, with OXY-BCN being unable to grow with a DUN diet even when actively feeding on it. GGEs (defined as the specific growth rates divided by the specific ingestion rate; both in C) were therefore null for this dinoflagellate on this diet, but were extremely high (75\%) when fed RHO. The GGEs for OXYCRB were $<20 \%$ for both diets, especially when feeding on DUN, irrespective of having the highest daily rations ( $>200 \%$ ). Regarding GYR, both strains showed much higher GGE when feeding on DUN (>50\%) than on RHO (16 to $22 \%$ ), although these dif- 
Table 4. Protozoan grazers Gyrodinium dominans (GYR-DK and GYR-BCN) and Oxyrrhis marina (OXY-BCN and OXYCRB) feeding on Rhodomonas salina (RHO) and Dunaliella tertiolecta (DUN) prey; results are averages of 3-4 replicates measured after $3 \mathrm{~d}$ acclimation to saturating conditions; standard errors are given in parentheses. IR = ingestion rate; $\mu=$ cell-based growth rate; GGE = carbon-based gross growth efficiency; DR = daily rations. GGE was calculated by dividing the daily carbon specific growth rate by the DR

\begin{tabular}{|lccccc|}
\hline Grazer & Prey & $\begin{array}{c}\text { IR (cells } \\
\left.\text { ind }{ }^{-1} \mathrm{~d}^{-1}\right)\end{array}$ & $\begin{array}{c}\mu \\
\left(\mathrm{d}^{-1}\right)\end{array}$ & $\begin{array}{c}\text { GGE } \\
(\%)\end{array}$ & $\begin{array}{c}\text { DR } \\
\left(\% \mathrm{~d}^{-1}\right)\end{array}$ \\
\hline GYR-DK & RHO & 13.3 & 0.17 & 21.9 & 91.2 \\
GYR-DK & DUN & $(0.21)$ & $(0.03)$ & $(5.3)$ & $(1.7)$ \\
& & $(2.75)$ & 0.23 & 61.4 & 51 \\
GYR-BCN & \multirow{2}{*}{ RHO } & 18.5 & 0.25 & 16.1 & 162.8 \\
& & $(0.21)$ & $(0.02)$ & $(1.6)$ & $(2.1)$ \\
GYR-BCN & DUN & 17 & 0.42 & 53.7 & 79.6 \\
& & $(0.58)$ & $(0.01)$ & $(2.5)$ & $(3.1)$ \\
OXY-BCN & \multirow{2}{*}{ RHO } & 24.8 & 0.44 & 75 & 79.7 \\
& & $(3.72)$ & $(0.06)$ & $(15)$ & $(21.6)$ \\
OXY-BCN & DUN & 14.3 & -0.04 & 0 & 87.6 \\
& & $(7.62)$ & $(0.05)$ & 0 & $(27.1)$ \\
OXY-CRB & \multirow{2}{*}{ RHO } & 27.6 & 0.39 & 19.8 & 200.8 \\
& & $(1.71)$ & $(0.04)$ & $(3.4)$ & $(14.3)$ \\
OXY-CRB & DUN & 79.6 & 0.33 & 9.3 & 368.7 \\
& & $(4.23)$ & $(0.04)$ & $(1.3)$ & $(22.7)$ \\
\hline
\end{tabular}

ferences were not significant in the case of GYR-DK due to the variability between replicates (ANOVA, Tukey-Kramer post hoc test). Overall, daily rations were higher for OXY, particularly for OXY-CRB, which exhibited daily rations $>200 \%$ (Table 4 ).

\section{Biochemical composition during starvation}

In Table 5, we summarize the $\mathrm{C}$ and $\mathrm{N}$ contents of all the organisms studied, along with the sum of total FA and alcohols (FA + Alc). Despite being a similar size, RHO has higher per cell $\mathrm{C}$ and $\mathrm{N}$ contents than DUN ( $t$-test, $\mathrm{p}<0.001)$. Conversely, the $\mathrm{C}: \mathrm{N}$ ratio of DUN was slightly higher than that of RHO (7.1 and 6.2 , respectively; $t$-test, $\mathrm{p}<0.001)$. FA + Alc per cell were $25 \%$ lower in DUN than in RHO ( $t$-test, $p<0.01$; Table 5), although the FA + Alc content per unit C was not significantly different $(\mathrm{p}=0.28)$. Regarding major FA composition, DUN and RHO presented quite contrasting profiles (Fig. 6), particularly of polyunsaturated FAs, given that EPA 20:5(n-3) and DHA 22:6(n-3) were absent in DUN. 18:3(n-3) and 18:2(n-6) were significantly higher in DUN (t-test, $\mathrm{p}<0.001$ ), while 18:4(n-3) was significantly higher in RHO ( $t$-test, $\mathrm{p}<0.001)$. Monounsaturated FA con-
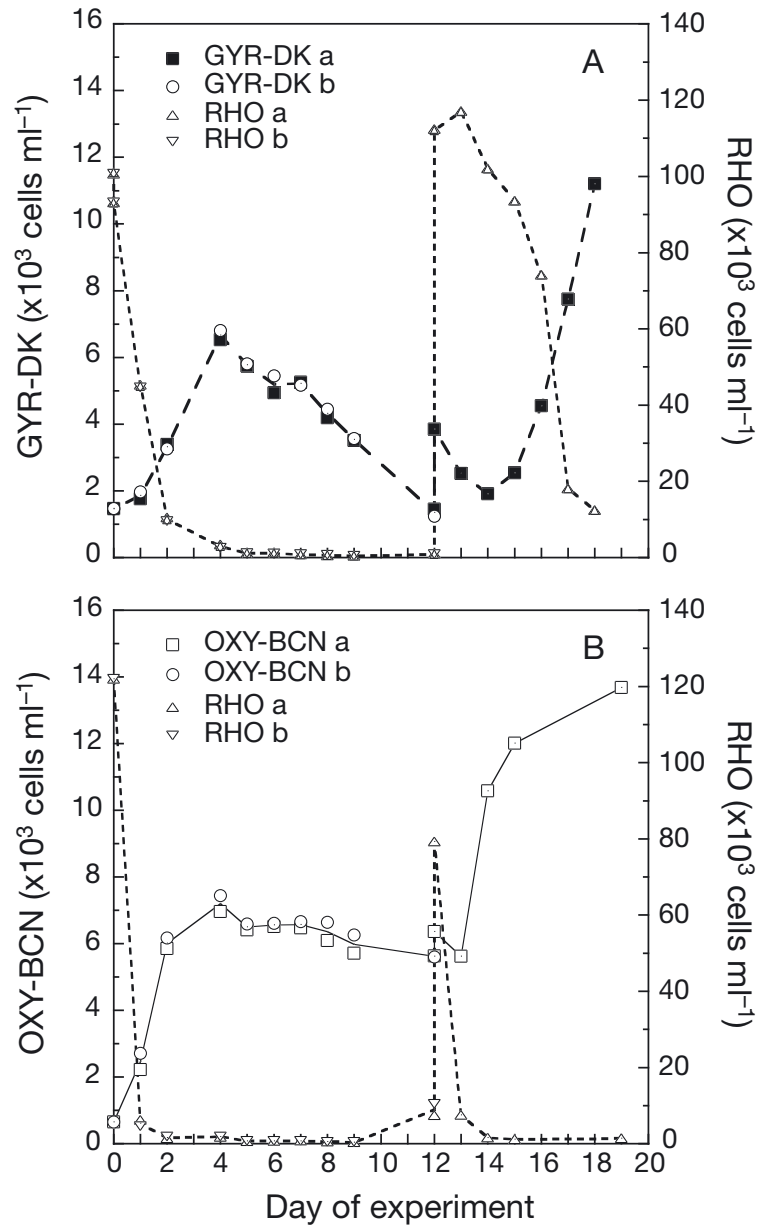

Fig. 5. Response of (A) Oxyrrhis marina (OXY-BCN) and (B) Gyrodinium dominans (GYR-DK) to starvation. Plots show the decay of prey Rhodomonas salina (RHO) and the response of 2 replicated bottles of grazers $(a, b)$ and the prey after the initial addition of prey, followed by another addition on Day 12

tents were also different for both algae, with DUN having significantly higher 18:1(n-9) content ( $t$-test, $\mathrm{p}<0.01$ ), and RHO having higher 18:1(n-7) content (t-test, $\mathrm{p}<0.001)$. Both algae had similar saturated FA contents, except for 16:0 (t-test, $\mathrm{p}<0.01)$.

The dinoflagellates had similar $\mathrm{C}: \mathrm{N}$ quotients (5.3 on average; 2-way repeated measures ANOVA, $\mathrm{p}=$ 0.22 ) irrespective of the diet, and maintained this ratio after $5 \mathrm{~d}$ of starvation (Table 5). After $2 \mathrm{~d}$ of starvation, we observed a certain decay of $\mathrm{C}$ and $\mathrm{N}$ per cell content of dinoflagellates; however, after $5 \mathrm{~d}$ of starvation GYR-BCN and both OXY strains showed an increase in the $\mathrm{C}$ and $\mathrm{N}$ contents per cell. Overall, GYR always presented less FA + Alc than OXY (both per cell and per $\mathrm{C}$ unit), feeding on either diet (2-way repeated measures ANOVA, p < 0.001). For both OXY strains, FA + Alc contents were higher 
Table 5. Carbon (C), nitrogen (N), and total fatty acids plus alcohols (FA + Alc) content of Rhodomonas salina (RHO), Dunaliella tertiolecta (DUN) and the 4 strains of dinoflagellates (Gyrodinium dominans; GYR-DK and GYR-BCN, and Oxyrrhis marina; OXY-BCN and OXY-CRB) on a diet of either RHO or DUN. Day 0 corresponds to the initial day of the experiment (Stage I), when the dinoflagellates showed prey inside their feeding vacuoles, but no prey were free in the water. Day 2 corresponds to $2 \mathrm{~d}$ of starvation (Stage II), when no traces of prey were visually detected inside the dinoflagellates. Day 5 corresponds to dinoflagellates starved for $5 \mathrm{~d}$ (Stage III). Maximum and minimum values and standard errors (SE) are given for duplicate and triplicate samples, respectively; nd = not determined

\begin{tabular}{|c|c|c|c|c|c|c|c|c|}
\hline Species & Day & $\begin{array}{c}\mathrm{C} \\
\left(\text { pg cell }^{-1}\right)\end{array}$ & Min.-Max. & $\begin{array}{c}\mathrm{N} \\
\left(\text { pg cell }^{-1}\right)\end{array}$ & Min.-Max. & $\mathrm{C} / \mathrm{N}$ & $\begin{array}{l}\mathrm{FA}+\mathrm{Alc} \\
\left(\mathrm{pg} \mathrm{cell}{ }^{-1}\right)\end{array}$ & $\mathrm{SE}$ \\
\hline DUN & 0 & 29.1 & $27.7-30.1$ & 4.8 & $4.5-5.0$ & 7.1 & 4.3 & 0.2 \\
\hline RHO & 0 & 42.4 & $41.3-43.9$ & 8.0 & $7.8-8.3$ & 6.2 & 5.8 & 0.2 \\
\hline GYR-DK on DUN & 0 & 432.5 & - & 97.9 & - & 5.2 & 17.8 & 0.6 \\
\hline GYR-DK on DUN & 2 & 388.2 & - & 83.1 & $81.5-84.7$ & 5.5 & 13.2 & 1.0 \\
\hline GYR-DK on DUN & 5 & 314.6 & $303.0-326.1$ & 67.1 & $64.8-69.3$ & 5.5 & 17.4 & 2.2 \\
\hline GYR-DK on RHO & 0 & 424.2 & $417.2-431.1$ & 94.3 & $93.8-94.9$ & 5.2 & 16.1 & 0.9 \\
\hline GYR-DK on RHO & 2 & 319.3 & $316.3-322.4$ & 75.2 & $73.2-77.1$ & 5.0 & 9.4 & 1.9 \\
\hline GYR-DK on RHO & 5 & 301.4 & $297.9-305.0$ & 67.9 & $67.3-68.5$ & 5.2 & 20.2 & 2.6 \\
\hline GYR-BCN on DUN & 0 & 367.5 & $336.3-398.8$ & 85.4 & $77.8-93.0$ & 5.0 & 21.2 & 2.0 \\
\hline GYR-BCN on DUN & 2 & 255.0 & $243.9-266.1$ & 51.7 & $49.2-54.2$ & 5.8 & 16.0 & 1.4 \\
\hline GYR-BCN on DUN & 5 & 317.2 & $300.2-334.2$ & 70.7 & $60.5-80.9$ & 5.3 & 19.1 & 4.7 \\
\hline GYR-BCN on RHO & 0 & 416.9 & $415.5-418.4$ & 85.3 & $85.3-85.3$ & 5.7 & 22.0 & 3.7 \\
\hline GYR-BCN on RHO & 2 & 284.0 & $278.8-289.2$ & 64.6 & $63.6-65.6$ & 5.1 & 17.9 & 5.7 \\
\hline GYR-BCN on RHO & 5 & 301.4 & $223.1-251.9$ & 67.9 & $47.0-55.3$ & 5.2 & 14.8 & 4.2 \\
\hline OXY-BCN on DUN & 0 & 547.0 & $522.8-571.3$ & 113.8 & $107.6-120.0$ & 5.6 & 133.5 & 16.6 \\
\hline OXY-BCN on DUN & 2 & nd & - & nd & - & nd & 90.9 & 5.9 \\
\hline OXY-BCN on DUN & 5 & 584.2 & $574.1-594.3$ & 127.5 & $120.4-134.5$ & 5.4 & 49.3 & 7.8 \\
\hline OXY-BCN on RHO & 0 & 492.4 & $469.3-515.5$ & 106.8 & $101.1-112.5$ & 5.4 & 81.3 & 9.2 \\
\hline OXY-BCN on RHO & 2 & 488.4 & $461.1-515.7$ & 111.7 & $106.2-117.1$ & 5.1 & 43.3 & 11.8 \\
\hline OXY-BCN on RHO & 5 & 595.6 & - & 126.8 & - & 5.5 & 16.8 & 2.4 \\
\hline OXY-CRB on DUN & 0 & 577.1 & $563.6-590.7$ & 128.0 & 125.9-130.1 & 5.3 & 154.7 & 4.8 \\
\hline OXY-CRB on DUN & 2 & 333.8 & $317.8-349.8$ & 72.9 & $67.1-78.6$ & 5.4 & 66.7 & 6.4 \\
\hline OXY-CRB on DUN & 5 & 407.5 & - & 89.3 & - & 5.3 & 49.2 & 4.0 \\
\hline OXY-CRB on RHO & 0 & 372.3 & $352.8-391.8$ & 80.9 & $79.6-82.2$ & 5.4 & 54.0 & 1.8 \\
\hline OXY-CRB on RHO & 2 & 283.9 & $279.0-288.8$ & 63.8 & $63.4-64.1$ & 5.2 & 18.9 & 0.4 \\
\hline OXY-CRB on RHO & 5 & 295.6 & $268.5-322.7$ & 67.4 & $61.3-73.6$ & 5.1 & 22.0 & 2.9 \\
\hline
\end{tabular}

when feeding on DUN than on RHO (2-way repeated measures ANOVA and Bonferroni post hoc test, $\mathrm{p}<$ 0.05), a trend not shared by the strains of GYR. All strains feeding on DUN had similar initial concentrations of DHA and lower concentrations than those accumulated when feeding on RHO, except OXYCRB, which showed more DHA when feeding on DUN (ANOVA, Tukey-Kramer post hoc test, $\mathrm{p}<0.05$; Fig. 6). On the other hand, all strains, except GYRDK, showed more EPA when feeding on RHO than on DUN. In all cases, both essential FA (DHA and EPA) were still present after $5 \mathrm{~d}$ starvation (Fig. 6). OXY was richer in DHA (absolute and relative amounts) and other FA (such as 18-carbon FAs and 16:0) than GYR; however, starvation resulted in their partial loss for both strains of OXY, especially during the first 48 h. Conversely, GYR kept the initial levels of total FA + Alc fairly constant throughout the starvation period, with the exception of GYR-BCN fed on RHO, which showed a reduction of EPA and DHA (Fig. 6).

\section{Respiration rates and metabolic balance}

Respiration rates and $\mathrm{C}$ demands were estimated for GYR-DK and the 2 strains of OXY. When feeding, the respiration activity was similar for GYR-DK and OXY-BCN $\left(1.1\right.$ and $1.2 \times 10^{-5} \mu \mathrm{mol} \mathrm{O} \mathrm{O}_{2} \mathrm{cell}^{-1} \mathrm{~d}^{-1}$, respectively), and lower for OXY-CRB $\left(8.8 \times 10^{-6} \mu \mathrm{mol}\right.$ $\mathrm{O}_{2}$ cell $^{-1} \mathrm{~d}^{-1}$; Table 6). When starving, respiration rates decreased by $75 \%$ in OXY-CRB, by $50 \%$ in GYR-DK, and by $30 \%$ in OXY-BCN (Table 6). In terms of $\mathrm{C}$ (assuming a respiratory quotient of 1 ), respiration rates in the presence of food accounted for 30 to $40 \%$ of the total C contents of the cell (Table 6). $\mathrm{C}$ assimilation efficiencies $\left(\mathrm{AE}_{;} \%\right)$, here defined as $(\mu \mathrm{c}+\mathrm{Rc}$ ) / Ic $\times 100$ (where $\mu \mathrm{c}$ and $I \mathrm{c}$ are the C-specific growth and ingestion rates, respectively; Kiørboe et al. 1985), were $28 \%$ for OXY-CRB, $69 \%$ for GYR-DK, and $103 \%$ for OXY-BCN. Assuming equal respiratory demands for GYR-DK and for GYR-BCN, the AE of the latter would be $39 \%$. 

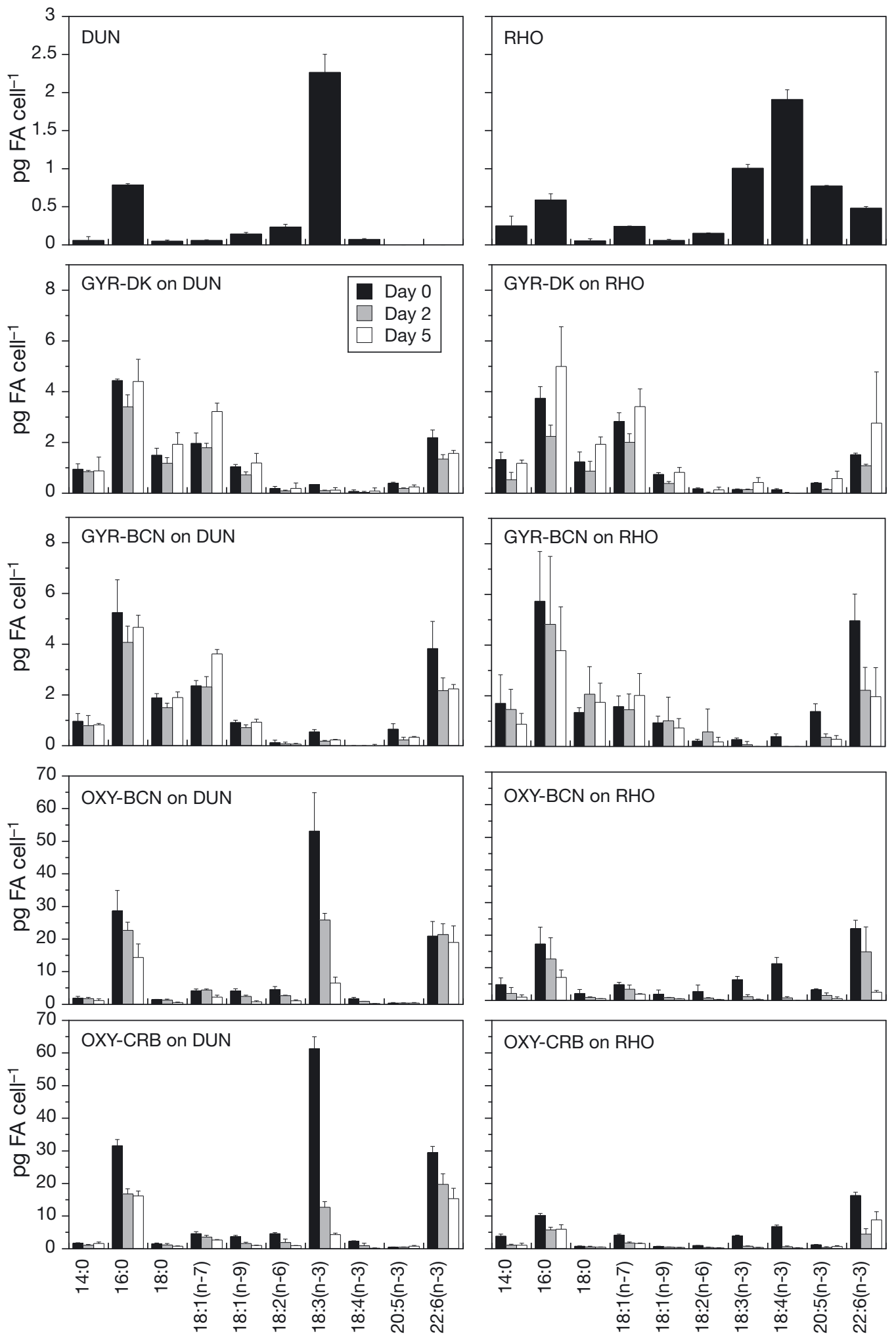

Fatty acid

Fig. 6. Major fatty acid concentrations ( $>5 \%$ of total concentration) for the 2 prey Rhodomonas salina (RHO) and Dunaliella tertiolecta (DUN) and the 4 strains of dinoflagellates Gyrodinium dominans (GYR-DK and GYR-BCN) and Oxyrrhis marina (OXY-BCN and OXY-CRB) on a diet based on either DUN or RHO. The different bars correspond to the different days of the starvation experiment (Days 0, 2, and 5) 
Table 6. Respiration rates of Gyrodinium dominans (GYR$\mathrm{DK})$ and Oxyrrhis marina (OXY-BCN and OXY-CRB) on a Rhodomonas salina (RHO) diet. $\mathrm{Ro}_{2}=$ with food; $\mathrm{R}^{*} \mathrm{O}_{2}=$ without food; $\mathrm{Rc}=$ carbon-specific respiration rates with food; $\mathrm{AE}=$ assimilation efficiency of food. Rc was computed based on the standard biomass of an unfed organism, even though it is referring to respiratory carbon demands when actively feeding (as shown for Day 2 in Table 5). The results are averages of 4 replicates; corresponding $\mathrm{SE}$ are given in parentheses below the values. AE was expressed as ( $\mu \mathrm{c}+\mathrm{Rc}) / \mathrm{IC}$ $\times 100$; where $\mu \mathrm{c}$ and $I \mathrm{c}=$ carbon-specific growth and ingestion rates, respectively

\begin{tabular}{|lcccc|}
\hline Grazer & $\begin{array}{c}\mathrm{Ro}_{2}(\mu \mathrm{mol} \\
\left.\mathrm{O}_{2} \mathrm{cell}^{-1} \mathrm{~d}^{-1}\right)\end{array}$ & $\begin{array}{c}\mathrm{R}^{*} \mathrm{o}_{2}(\mu \mathrm{mol} \\
\left.\mathrm{O}_{2} \mathrm{cell}^{-1} \mathrm{~d}^{-1}\right)\end{array}$ & $\begin{array}{c}\mathrm{RC} \\
\left(\mathrm{d}^{-1}\right)\end{array}$ & $\begin{array}{c}\mathrm{AE} \\
(\%)\end{array}$ \\
\hline GYR-DK & $1.1 \times 10^{-5}$ & $5.2 \times 10^{-6}$ & 0.41 & 69 \\
& $\left(5.4 \times 10^{-7}\right)$ & $\left(9.3 \times 10^{-7}\right)$ & -0.023 & \\
OXY-BCN & $1.2 \times 10^{-5}$ & $4.0 \times 10^{-6}$ & 0.3 & 103 \\
& $\left(6.6 \times 10^{-7}\right)$ & $\left(3.4 \times 10^{-7}\right)$ & -0.014 & \\
OXY-CRB & $8.8 \times 10^{-6}$ & $6.5 \times 10^{-6}$ & 0.4 & 28 \\
& $\left(4.3 \times 10^{-7}\right)$ & $\left(4.5 \times 10^{-7}\right)$ & -0.018 & \\
& & & & \\
\hline
\end{tabular}

\section{DISCUSSION}

\section{Feeding responses to food quantity}

We found clear differences between species, and between OXY-BCN and OXY-CRB, in terms of responses to food quantity. Conversely, GYR-BCN and GYR-DK fed at similar rates. The rates found in this study fall within those reported by Goldman et al. (1989), Roberts et al. (2011), and Nakamura et al. (1995) for OXY feeding on a variety of prey, and for overall heterotrophic dinoflagellates summarized by Jeong et al. (2010). However, they are lower than the specific values presented by Schmoker et al. (2011) and the per cell rates shown in Hantzsche \& Boersma (2010) for GYR and OXY, respectively, feeding on RHO. The discrepancies between these specific works and our results will be discussed later.

As reported by Schmoker et al. (2011), we also observed a drop in ingestion rates of GYR at high prey concentrations. This may indicate that this species does not thrive well in eutrophic conditions, in contrast to OXY, which keeps feeding at maximum rates even at very high prey concentrations. In fact, when grown in culture, OXY can be fed with very high concentrations of prey, whereas GYR needs to be maintained at low food levels to maximize survival (authors' pers. obs.). The mechanisms behind these differences remain unknown, although they may be linked to the low tolerance of GYR to high $\mathrm{pH}$, as occurs during episodes of high phytoplankton abundance and production (Pedersen \& Hansen
2003). On the other hand, both OXY strains also saturated feeding at lower concentrations compared to GYR, which suggests an adaptation to lower food scenarios as well. Altogether, these findings suggest that OXY is better adapted to extreme situations in food availability than GYR.

\section{Adaptations to feast and famine}

Although GYR is able to accommodate very large prey into its body, such as diatom chains (Nakamura et al. 1995; A. Calbet pers. obs.), feeding on small prey seems to limit the intake of food to very few items per hour, whereas OXY fills its entire cell with prey. It seems that the different strategy of small prey ingestion observed here for GYR and OXY does not necessarily rely on dissimilarities of their body plasticity, but likely on behavioral differences of detection and capture of prey and prey handling time. Whatever the mechanism responsible for such a difference, it is unquestionable that the strategy adopted by OXY gives the species an advantage when facing patches of food, reinforcing its opportunistic behavior. Moreover, its slow digestion time (Klein et al. 1986, Öpik \& Flynn 1989) and capacity for food storage favors the division of the organism, even when no more food is present (Flynn \& Mitra 2009; this study), and thus increases the probability of encountering a new patch of food (Fenchel 1989). These characteristics afford the species (or at least to some strains within the species) an array of advantages for survival in food quantity and quality heterogeneous or fluctuating environments, such as rock pools and salt marshes. In these environments, the speed of capture of food and the capacity for storage can be crucial, as opposed to open waters where a body full of prey may increase the individual's conspicuousness to predators.

Regarding other metabolic aspects, the $\mathrm{AE}$ and the $\mathrm{C}$ allocated to growth in OXY-BCN were extremely high when feeding on the suitable prey (RHO). Certainly, values near $100 \%$ of the C assimilated are obviously unrealistic, but it is beyond doubt that their efficiency is very high compared to other protozoans and metazoans (Hansen et al. 1997). Also, the decrease in respiratory activity when not feeding was rather high for OXY-BCN compared to the other strains, although these adaptations were not shared by the strain OXY-CRB, which seemed to have different adaptations to heterogeneous food environments (i.e. low metabolic demands, better capacity to take advantage of nutritionally poor diets, higher maximum daily rations, etc.). 
GYR can also take advantage of discrete food supply, as demonstrated by Schmoker et al. (2011), and by the evidence found in this study. For instance, it also showed some short-term superfluous feeding when previously starved; although to a lower extent than OXY. Nevertheless, in light of the data presented here, OXY would likely out-compete GYR in their capability to quickly ingest and store food in a heterogeneous or fluctuating food environment.

All the adaptations discussed here seem to be pointing towards the resistance of the species to suboptimal environments. This fact was especially evident by the low mortality observed for OXY-BCN when starved for more than a week. Assuming a constant mortality rate during starvation (which does not necessarily have to be the case) OXY-BCN would require $50 \mathrm{~d}$ to completely vanish from our culture. Our previous experience with this strain actually points towards much longer survival times when left unfed (ca. 2 yr), likely feeding cannibalistically or on bacteria (Jeong et al. 2008), and perhaps enduring periods of scarcity of food encysted (Montagnes et al. 2011). Obviously, there is no record of any dinoflagellate that can survive for such long periods in filtered sea water, and in nature this scenario would be unrealistic. The longest periods of survival to starvation reported are of $71 \mathrm{~d}$ for Protoperidinium depressum on a diatom diet at $<1 \mu \mathrm{g} \mathrm{C} 1^{-1}$ (Menden-Deuer et al. 2005). Strom (1991) also reported that an athecate dinoflagellate resisted $30 \mathrm{~d}$ of starvation. However, in most situations, protozoans (mainly ciliates) usually do not survive more than a few days of starvation (Jackson \& Berger 1984, Fenchel 1990, Jakobsen \& Hansen 1997). As suggested by Menden-Deuer et al. (2005), the differences between species may be in the ability to allocate part of the energy into storage products such as lipidic compounds; a subject that will be addressed below.

\section{Feeding and growth responses to food quality}

Heterotrophic dinoflagellates, and protozoans in general, show different feeding responses when offered diverse prey, with prey size likely being the most immediate specific characteristic affecting feeding behavior. Concerning the species chosen, OXY can feed on cells 0.5 to $20 \mu \mathrm{m}$ in size (Schumann et al. 1994, Nakamura et al. 1995, Jeong et al. 2010, Roberts et al. 2011), in contrast to other naked dinoflagellates, including GYR, with a higher upper prey size limit (up to $43 \mu \mathrm{m}$, Naustvoll 2000; long diatom chains, Nakamura et al. 1995). Yet food quality may also play a pivotal role in feeding performance. For instance, when confronted with mixtures of microalgae, the ciliate Balanion sp. fed preferentially on the prey that supported its fastest growth (Stoecker et al. 1986). OXY showed lower per cell ingestion rates on $\mathrm{P}$-deficient $\mathrm{RHO}$, although the differences became non-significant when cellular volume was considered (Hantzsche \& Boersma 2010). In a similar recent study, Meunier et al. (2012b) observed selective feeding of OXY on phosphorus-rich RHO. In addition, OXY has been found to reject Isochrysis sp. on occasion, which was associated with elevated C:N ratios in the prey (Flynn et al. 1996).

When comparing a grazer's performance to prey quality it is crucial to choose prey of similar size and motility, in order to restrict the variables affecting feeding and growth rates. In our case, we tried to go one step further and chose prey of similar shape, size and motility, as well as stoichiometric proportion (Brutemark et al. 2009), restricting the major differences most likely to their FA composition and other biochemical compounds (Klein Breteler et al. 1999, 2004, Veloza et al. 2006, Chu et al. 2008a,b, Lund et al. 2008). Our data show that when both prey were offered to starved dinoflagellates, OXY-BCN fed on RHO at higher specific rates than on DUN, whereas GYR-DK ingested RHO and DUN at similar maximum rates. It seems, therefore, that through increased ingestion rate dinoflagellates optimize nutrient assimilation by extracting the easily digestible part of their food. However, when preconditioned in an excess of food, OXY-CRB fed at higher rates on the 'less nutritious prey'. This response may be interpreted as superfluous or compensatory feeding, previously observed in OXY to compensate for nutritional imbalances of prey (Meunier et al. 2012b). Nevertheless, the resulting GGE were lower when feeding on less nutritious prey than when feeding on $\mathrm{RHO}$, indicating the former diet was not optimal for this species. Regarding GYR, we found the exactly opposite situation for both strains, which displayed higher daily rations on RHO but higher GGE on DUN. Therefore, both strains of GYR seemed to be taking more advantage of the prey deficient in the DHA and EPA. We can not associate this feeding selection and growth performance strictly to lipid composition, however, since other essential biochemical compounds not considered here could be shedding some light into the paradox. For instance (and only as an example of a mechanism that could be relevant), OXY does not modify dietary ${ }^{13} \mathrm{C}$-cholesterol, whereas GYR has the ability to desaturate and alkylate dietary cholesterol (Lund et al. 2009). To what extent these biochemical pro- 
cesses are universal for the species or only for some strains remains unknown. There is previous evidence supporting different lipid composition and biochemical origin in several strains of the dinoflagellate Karlodinium beneficum (Calbet et al. 2011), suggesting that the biochemistry of these, and other compounds, may be highly strain-specific.

\section{Biochemical differences between predator and prey}

Our FA analysis corroborated previous reports on DUN, indicating that this alga lacks EPA and DHA (Klein Breteler et al. 1999, Koski \& Klein Breteler 2003, Lund et al. 2008, Jónasdóttir et al. 2009). Not anticipated, however, were the different responses in the biochemical composition of the starving dinoflagellates. These differences were not evident in terms of $\mathrm{C}$ and $\mathrm{N}$ because after $2 \mathrm{~d}$ of food deprivation, the amount of $\mathrm{C}$ and $\mathrm{N}$ per cell decreased proportionally for all the strains. It was, however, surprising that after $5 \mathrm{~d}$ of starvation, some of the dinoflagellate strains showed an increase in $\mathrm{C}$ and $\mathrm{N}$ contents per cell. We attribute this increase to either the consumption of bacteria that may have grown in the experiment after the long incubation time, or to the presence of some detritus in the filtrates. As a consequence of this result, we decided to use Day 2 of starving conditions as standard for the biomass of unfed organisms, and include it in our $\mathrm{C}$ budget calculations and $\mathrm{C}$-specific ingestion rates (except for OXY-BCN feeding on DUN, where Day 5 was used because no data were available for Day 2).

For well-fed organisms, our results on FA contents do not differ considerably from previous studies on the subject (Klein Breteler et al. 1999, Veloza et al. 2006, Chu et al. 2008b, Bec et al. 2010); i.e. when the dinoflagellates were fed on DUN they showed similar amounts of DHA (even if EPA was generally present at lower concentrations) to those grown on the RHO diet. In the large majority of protists, polyunsaturated fatty acids (PUFAs) are produced by a series of aerobic desaturations and elongations of the 16 and $18 \mathrm{FA}$ (Desvilettes \& Bec 2009). In fact, GYR strains had significantly lower levels of 18:3(n-3) compared to DUN; hence, we may assume a modification of this FA to EPA and further to DHA by elongation and desaturation of 18:3(n-3), a result in agreement with Veloza et al. (2006). For OXY, on the other hand, the production of the essential FAs did not follow the classic pathway i.e. elongation and desaturation of 18:3(n-3), as the levels of 18:3(n-3) were significantly higher when fed on DUN than when fed on RHO, and were approximately the same as DUN (around 45 to $50 \%$ ). This seems to contradict the results of Parrish et al. (2012), who reported lower levels of 18:3(n-3) in their OXY strain compared to its autotrophic food source, indicating an upgrading via the classic pathway.

Apart from this pathway of production of essential FAs there are other, more uncommon pathways, such as the polyketide-like PUFA synthase (Matsuda et al. 2012), or even de novo synthesis of PUFAs (Bec et al. 2006, Lund et al. 2008). The pathways for biochemical food alteration of heterotrophic dinoflagellates seem to be species- and even strain-specific, and can be used concomitantly by the same organism.

\section{Biochemical changes during starvation and consequences for trophic upgrading}

The protozoans feeding on rich and poor algae preferentially accumulated DHA over EPA, supporting that the latter FA serves as a fuel for metabolism or it is used to produce DHA, for which there can be a higher demand (Veloza et al. 2006). However, when starved, both species metabolized FA in a different way. A certain degree of FA loss was expected between Days 0 and 2, because the dinoflagellates had still undigested cells inside, and because the amount of FA per cell should decrease when grazers were actively dividing (first $48 \mathrm{~h}$ ). After the complete digestion of prey (Day 2), and in the absence of cell duplication, any variability in the FA contents should be resulting from catabolic use. OXY lost substantial total FA between Days 2 and 5 of starvation, whereas GYR kept somewhat similar levels throughout the experiment; however, the levels of DHA and EPA remained quite constant for all the dinoflagellate strains (with the exception of OXY-BCN fed on RHO). Such contrasting metabolic responses may have severe consequences for the overall survival success of the different species when facing starvation. One could argue that a priori, keeping the FA as reserves may prolong the survival time of GYR when food is scare. However, our experiments on survival to starvation showed the opposite. Considering that both species show similar respiratory $\mathrm{C}$ demands, perhaps GYR satisfies its $\mathrm{C}$ demands from other notso-expendable compounds (e.g. proteins and carbohydrates), whereas OXY mostly burns out the fat reserves. This seems to contrast with the recent work of Meunier et al. (2012b), who showed that during starvation, $\mathrm{N}$-depleted OXY used lipids as an energy source, whereas $\mathrm{N}$-rich OXY, such as the ones used 
in the present study, also required proteins as a source for respiration.

It can be argued that the variations in FA during starvation may have consequences for microzooplankton-mediated food upgrading for higher trophic level consumers. Therefore, the importance of food upgrading may theoretically be compromised for those species using lipids as the major fuel for respiration (i.e. OXY), in sites where food for microzooplankton is scarce. However, our results indicate that under periods of starvation of less than $5 \mathrm{~d}$ the studied dinoflagellates maintain a certain level of trophic upgrading; although, certainly, the nutritional value of the dinoflagellates (especially OXY strains) decreased after starvation.

\section{Variability within strains}

In the past years, the need to work with different strains of the same species of protists has been emphasized in the literature, in order to better understand the variability within species and the ecological benefits and constraints they might reveal. Different strains of autotrophic dinoflagellates have shown significant dissimilarities in their performance (e.g. growth, feeding and survival), and in their biochemical composition (Wood \& Leatham 1992, Adolf et al. 2007, Lakeman et al. 2009, Tillmann et al. 2009, Calbet et al. 2011). However, studies on different strains of heterotrophic dinoflagellates are relatively scarce. Specifically for OXY and GYR, there are some studies that point out the relevant differences between strains (e.g. Nakamura et al. 1995, Lowe et al. 2010, Watts et al. 2011, Parrish et al. 2012). The differences between our strains were also evident, especially in the case of OXY-CRB and OXY-BCN. In fact, both strains have been classified as different clades (Lowe et al. 2010, Watts et al. 2011), and it has even been suggested that they may be different species (i.e. Oxyrrhis marina and O. maritima; Lowe et al. 2011). We are unaware of similar phylogenetic studies for GYR, however, our strains seem to be quite close, at least on the phenotypic and functional characteristics studied here, although they showed slight differences in lipid composition and energy source during starvation.

\section{Implications of our results for grazing experiments}

Our experiment on the short-term feeding response of dinoflagellates to a pulse of food revealed a quick decay in the feeding rates of OXY (and to some extend of GYR) during the incubation, which may result in overestimations of feeding rates when short term incubations are conducted. For instance, if only the first hour of our incubation were considered for calculating the feeding rates, OXY would feed at ca. 400 RHO grazer ${ }^{-1} \mathrm{~d}^{-1}$ ( 7 times higher than the maximum ingestion rate if integrated for $24 \mathrm{~h}$, and 14 times higher than when acclimated). The differences for GYR were not so conspicuous, but important enough to deserve consideration. Consequently, this particular response could explain the previously mentioned differences between our functional responses (24 h incubations) with OXY and those of Hantzsche \& Boersma (2010) and others using short incubation times, although it does not explain the disparity of results with GYR reported by Schmoker et al. (2011). We believe the differences between the latter work and ours are simply driven by the different $\mathrm{C}$ to volume conversion factors, since in terms of GGE, both data sets are quite similar.

When working with species that show compensatory feeding rates in response to changes in food quality (Meunier et al. 2012b) and quantity (present study), it is of paramount importance to conduct long incubations, and to have knowledge of the previous feeding history. We recommend $24 \mathrm{~h}$ incubations, to include possible daily feeding cycles (Jakobsen \& Strom 2004), and preconditioning the organisms to each food level for several days. Where preconditioning is not feasible, we suggest taking the initial samples for the grazing rate computation at least $2 \mathrm{~h}$ after predator and prey are combined, to allow for stabilization of the feeding rates.

Regarding GGE and other biomass specific rates (e.g. respiration, ingestion, growth), we should keep in mind that, due to the plasticity of the cell membrane of both species (especially OXY), a calculation of the specific rates based on biovolume or $\mathrm{C}$ when the dinoflagellates have been incubated with food would bias the results. Undigested material inside the cell, as a consequence of long digestion times and large vacuole contents, should not be included in the biomass of the organism.

\section{CONCLUSIONS}

Our first hypothesis proposed that OXY would show better performance than GYR under heterogeneous food conditions, and this was verified in our experiments. The second hypothesis referred to the response of both species when presented with a lipid- 
deficient prey. We proposed that, for both species, there would be a detrimental effect on growth rates. Here we found some supporting evidence for OXY, but not for GYR. To summarize, OXY (especially OXY-BCN) seems to be more opportunistic and follows an $r$-strategy, which is typical of unstable and heterogeneous environments, although there are clear differences between strains. The high degree of tolerance to many other environmental factors not studied here also backs up this statement. For instance, OXY tolerates a wide range of $\mathrm{pH}$, in contrast to GYR which reduces growth at high $\mathrm{pH}(>9.2 \mathrm{pH}$; Pedersen \& Hansen 2003). The salinity range of OXY is also quite broad, spanning from 4 to $60 \mathrm{psu}$, although there are considerable differences among strains (Zhang et al. 2010). Together, these factors make OXY a clear survivor in heterogeneous and fluctuating environments.

Acknowledgements. This research was funded by project PROTOS (CTM2009-08783) from the Spanish Ministry of Science and Innovation assigned to A.C. and it is a contribution of the Marine Zooplankton Ecology Excellence Group from the Generalitat de Catalunya (2009SGR-1283). R.A.M. was funded by a PhD fellowship from the National Commission of Science (CONICYT), Ministry of Education, Chile. S.G. was supported by an FCT Post-doctoral Fellowship (SFRH/BPD/38332/2007) and Project VITAL (FCT PTDC/ MAR/111304/2009). We thank Dr. H. H. Jakobsen for providing the strain of GYR-DK, and together with 2 anonymous reviewers, improving the manuscript with their comments. J. Lütke is acknowledged for his valuable support in lipid analyses.

\section{LITERATURE CITED}

$>$ Adolf JE, Krupatkina D, Bachvaroff T, Place AR (2007) Karlotoxin mediates grazing by Oxyrrhis marina on strains of Karlodinium veneficum. Harmful Algae 6: $400-412$

- Almeda R, Alcaraz M, Calbet A, Saiz E (2011) Metabolic rates and carbon budget of early developmental stages of the marine cyclopoid copepod Oithona davisae. Limnol Oceanogr 56:403-414

$>$ Bec A, Martin-Creuzburg D, von Elert E (2006) Trophic upgrading of autotrophic picoplankton by the heterotrophic nanoflagellate Paraphysomonas sp. Limnol Oceanogr 51: 1699-1707

> Bec A, Martin-Creuzburg D, Von Elert E (2010) Fatty acid composition of the heterotrophic nanoflagellate Paraphysomonas sp.: influence of diet and de novo biosynthesis. Aquat Biol 9:107-112

$>$ Begun AA, Orlova TY, Selina MS (2004) A 'bloom' in the water of Amursky Bay (Sea of Japan) caused by the dinoflagellate Oxyrrhis marina Dujardin, 1841. Russ J Mar Biol 30:51-55

Brutemark A, Lindehoff E, Granéli E, Granéli W (2009) Carbon isotope signature variability among cultured microalgae: influence of species, nutrients and growth. J Exp
Mar Biol Ecol 372:98-105

Calbet A, Bertos M, Fuentes-Grunewald C, Alacid E, Figueroa R, Renom B, Garces E (2011) Intraspecific variability in Karlodinium veneficum: growth rates, mixotrophy, and lipid composition. Harmful Algae 10: 654-667

> Cavalier-Smith T, Chao E (2004) Protalveolate phylogeny and systematic and the origins of Sporozoa and dinoflagellates (phylum Myzozoa nom. nov.). Eur J Protistol 40: 185-212

Chu FLE, Lund ED, Littreal PR, Ruck KE and others (2008a) Sterol production and phytosterol bioconversion in two species of heterotrophic protists, Oxyrrhis marina and Gyrodinium dominans. Mar Biol 156:155-169

$>$ Chu FLE, Lund ED, Podbesek JA (2008b) Quantitative significance of $\mathrm{n}-3$ essential fatty acid contribution by heterotrophic protists in marine pelagic food webs. Mar Ecol Prog Ser 354:85-95

Desvilettes C, Bec A (2009) Formation and transfer of fatty acids in aquatic microbial food webs: role of heterotrophic protists. In: Arts MT, Brett MT, Kainz MJ (eds) Lipids in aquatic ecosystems. Springer Science and Business Media, New York, NY, p 25-42

Droop MR (1953) On the ecology of flagellates from some brackish and fresh water rockpools of Finland. Acta Bot Fenn 51:1-52

$>$ Fenchel T (1982) Ecology of heterotrophic microflagellates. II. Bioenergetics and growth. Mar Ecol Prog Ser 8: 225-231

Fenchel $\mathrm{T}$ (1989) Adaptations to a feast and famine existence in protozoa. In: Wieser W, Gnaiger G (eds) Energy transformation in cells and organisms. Georg Thieme Verlag, Stuttgart, p 290-295

Fenchel T (1990) Adaptive significance of polymorphic life cycles in Protozoa: responses to starvation and refeeding in two species of marine ciliates. J Exp Mar Biol Ecol 136:159-177

> Flynn KJ, Mitra A (2009) Building the 'perfect beast': modelling mixotrophic plankton. J Plankton Res 31:965-992

> Flynn KJ, Davidson K, Cunningham A (1996) Prey selection and rejection by a microflagellate; implications for the study and operation of microbial food webs. J Exp Mar Biol Ecol 196:357-372

Folch J, Lees M, Sloane-Stanley GH (1957) A simple method for isolation and purification of total lipids from animal tissues. J Biol Chem 226:497-509

Frost BW (1972) Effects of size and concentration of food particles on the feeding behavior of the marine planktonic copepod Calanus pacificus. Limnol Oceanogr 17: 805-815

- Goldman JC, Dennett MR, Gordin H (1989) Dynamics of herbivorous grazing by the heterotrophic dinoflagellate Oxyrrhis marina. J Plankton Res 11:391-407

Guillard RRL (1975) Culture of phytoplankton for feeding marine invertebrates. In: Smith WL, Chanley MH (eds) Culture of marine invertebrate animals. Plenum Press, New York, NY, p 29-60

> Hansen J (1992) Prey size selection, feeding rates and growth dynamics of heterotrophic dinoflagellates with special emphasis on Gyrodinium spirale. Mar Biol 114: 327-334

- Hansen G, Daugbjerg N (2004) Ultrastructure of Gyrodinium spirale, the type species of Gyrodinium (Dinophyceae), including a Phylogeny of G. dominans, G. rubrum and G. spirale deduced from partial LSU rDNA 
sequences. Protist 155:271-294

> Hansen PJ, Bjørnsen PK, Hansen BW (1997) Zooplankton grazing and growth: Scaling within the 2-2000 mm body size range. Limnol Oceanogr 42:687-704

> Hantzsche FM, Boersma M (2010) Dietary-induced responses in the phagotrophic flagellate Oxyrrhis marina. Mar Biol 157:1641-1651

Haury LR, McGowan JA, Wiebe PH (1978) Patterns and processes in the time-scales of plankton distributions. In: Steel JH (ed) Spatial patterns in plankton communities. Plenum Press, New York, NY, p 277-327

$>$ Heinbokel JF (1978) Studies on the functional role of tintinnids in the Southern California Bight. I. Grazing and growth rates in laboratory cultures. Mar Biol 47:177-189

> Jackson KM, Berger J (1984) Survival of ciliated protozoa under starvation conditions and at low bacterial levels. Microb Ecol 10:47-59

> Jakobsen H, Hansen P (1997) Prey size selection, grazing and growth response of the small heterotrophic dinoflagellate Gymnodinium sp. and the ciliate Balanion comatum-a comparative study. Mar Ecol Prog Ser 158: $75-86$

> Jakobsen HH, Strom SL (2004) Circadian cycles in growth and feeding rates of heterotrophic protist plankton. Limnol Oceanogr 49:1915-1922

> Jeong HJ, Seong KA, Yoo YD, Kim TH and others (2008) Feeding and grazing impact by small marine heterotrophic dinoflagellates on heterotrophic bacteria. J Eukaryot Microbiol 55:271-288

> Jeong HJ, Yoo YD, Kim JS, Seong KA, Kang NS, Kim TH (2010) Growth, feeding and ecological roles of the mixotrophic and heterotrophic dinoflagellates in marine planktonic food webs. Ocean Sci J 45:65-91

> Jeong HJ, Kim TH, Yoo YD, Yoon EY and others (2011) Grazing impact of heterotrophic dinoflagellates and ciliates on common red-tide euglenophyte Eutreptiella gymnastica in Masan Bay, Korea. Harmful Algae 10: 576-588

> Johnson MP (2000) Physical control of plankton population abundance and dynamics in intertidal rock pools. Hydrobiologia 440:145-152

> Jónasdóttir SH, Visser AW, Jespersen C (2009) Assessing the role of food quality in the production and hatching of Temora longicornis eggs. Mar Ecol Prog Ser 382:139-150

> Jonsson PR (1994) Tidal rhythm of cyst formation in the rock pool ciliate Strombidium oculatum Gruber (Ciliophora, Oligotrichida): a description of the functional biology and an analysis of the tidal synchronization of encystment. J Exp Mar Biol Ecol 175:77-103

> Kattner G, Fricke HSG (1986) Simple gas-liquid chromatography method for simultaneous determination of fatty acids and alcohols in wax esters of marine organisms. J Chromatogr A 361:263-268

Kim JS, Jeong HJ (2004) Feeding by the heterotrophic dinoflagellates Gyrodinium dominans and G. spirale on the red-tide dinoflagellate Prorocentrum minimum. Mar Ecol Prog Ser 280:85-94

Kiørboe T, Mohlenberg F, Hamburger K (1985) Bioenergetics of the planktonic copepod Acartia tonsa: relation between feeding, egg production and respiration and composition of specific dynamic action. Mar Ecol Prog Ser 26:85-97

Klein B, Gieskes WWC, Kraay GG (1986) Digestion of chlorophylls and carotenoids by the marine protozoan Oxyrrhis marina studied by h.p.l.c. analysis of algal pig- ments. J Plankton Res 8:827-836

> Klein Breteler WCM, Schogt N, Baas M, Schouten S, Kraay GW (1999) Trophic upgrading of food quality by protozoans enhancing copepod growth: role of essential lipids. Mar Biol 135:191-198

Klein Breteler WCM, Koski M, Rampen S (2004) Role of essential lipids in copepod nutrition: no evidence for trophic upgrading of food quality by a marine ciliate. Mar Ecol Prog Ser 274:199-208

> Koch AL (1971) The adaptive responses of Escherichia coli to a feast and famine existence. Adv Microb Physiol 6: 147-217

Koski M, Klein Breteler WCM (2003) Influence of diet on copepod survival in the laboratory. Mar Ecol Prog Ser 264:73-82

Lakeman MB, von Dassow P, Cattolico RA (2009) The strain concept in phytoplankton ecology. Harmful Algae 8: 746-758

> Lowe CD, Day A, Kemp SJ, Montagnes DJS (2005) There are high levels of functional and genetic diversity in Oxyrrhis marina. J Eukaryot Microbiol 52:250-257

> Lowe CD, Montagnes DJS, Martin LE, Watts PC (2010) Patterns of genetic diversity in the marine heterotrophic flagellate Oxyrrhis marina (Alveolata: Dinophyceae). Protist 161:212-221

Lowe CD, Keeling PJ, Martin LE, Slamovits CH, Watts PC, Montagnes DJS (2011) Who is Oxyrrhis marina? Morphological and phylogenetic studies on an unusual dinoflagellate. J Plankton Res 33:555-567

Lund ED, Chu FLE, Harvey E, Adlof R (2008) Mechanism(s) of long chain n-3 essential fatty acid production in two species of heterotrophic protists: Oxyrrhis marina and Gyrodinium dominans. Mar Biol 155:23-36

Lund ED, Chu FLE, Littreal PR, Ruck KE, Harvey E (2009) An investigation of the mechanisms for sterol synthesis and dietary sterol bioconversion in the heterotrophic protists Oxyrrhis marina and Gyrodinium dominans. J Exp Mar Biol Ecol 374:150-159

Mackas DL, Denman KL, Abbott MR (1985) Plankton patchiness: biology in the physical vernacular. Bull Mar Sci 37 : 652-674

Martins GM, Hawkins SJ, Thompson RC, Jenkins SR (2007) Community structure and functioning in intertidal rock pools: effects of pool size and shore height at different successional stages. Mar Ecol Prog Ser 329:43-55

> Matsuda T, Sakaguchi K, Hamaguchi R, Kobayashi T and others (2012) Analysis of $\Delta 12$-fatty acid desaturase function revealed that two distinct pathways are active for the synthesis of PUFAs in T. aureum ATCC 34304. J Lipid Res 53:1210-1222

> Menden-Deuer S, Lessard EJ, Satterberg J, Grünbaum D (2005) Growth rates and starvation survival of three species of the pallium-feeding, thecate dinoflagellate genus Protoperidinium. Aquat Microb Ecol 41:145-152

> Metaxas A, Scheibling RE (1993) Community structure and organization of tidepools. Mar Ecol Prog Ser 98: 187-198

> Meunier CL, Haafke J, Oppermann B, Boersma M, Malzahn AM (2012a) Dynamic stoichiometric response to food quality fluctuations in the heterotrophic dinoflagellate Oxyrrhis marina. Mar Biol 159:2241-2248

> Meunier CL, Hantzsche FM, Cunha-Dupont AO, Haafke J, Oppermann B, Malzahn AM, Boersma M (2012b) Intraspecific selectivity, compensatory feeding and flexible homeostasis in the phagotrophic flagellate Oxyrrhis 
marina: three ways to handle food quality fluctuations. Hydrobiologia 680:53-62

Meyer-Reil LA, Bolter M, Liebezeit G, Schramm W (1979) Short-term variations in microbiological and chemical parameters. Mar Ecol Prog Ser 1:1-6

Montagnes DJS, Lowe CD, Roberts EC, Breckels MN and others (2011) An introduction to the special issue: Oxyrrhis marina, a model organism? J Plankton Res 33: 549-554

Motulsky H, Christopoulos A (2003) Fitting models to biological data using linear and nonlinear regression. A practical guide to curve fitting. GraphPad Software, San Diego, CA

Nakamura Y, Suzuki SY, Hiromi J (1995) Growth and grazing of a naked heterotrophic dinoflagellate, Gyrodinium dominans. Aquat Microb Ecol 9:157-164

Naustvoll LJ (2000) Prey size spectra in naked heterotrophic dinoflagellates. Phycologia 39:448-455

Öpik H, Flynn KJ (1989) The digestive process of the dinoflagellate, Oxyrrhis marina Dujardin, feeding on the chlorophyte, Dunaliella primolecta Butcher: a combined study of ultrastructure and free amino acids. New Phytol 113:143-151

Parrish CC, French VM, Whiticar MJ (2012) Lipid class and fatty acid composition of copepods (Calanus finmarchicus, C. glacialis, Pseudocalanus sp., Tisbe furcata and Nitokra lacustris) fed various combinations of autotrophic and heterotrophic protists. J Plankton Res 34:356-375

Pedersen MF, Hansen PJ (2003) Effects of high pH on the growth and survival of six marine heterotrophic protists. Mar Ecol Prog Ser 260:33-41

Peters J, Renz J, van Beusekom J, Boersma M, Hagen W (2006) Trophodynamics and seasonal cycle of the copepod Pseudocalanus acuspes in the Central Baltic Sea (Bornholm Basin): evidence from lipid composition. Mar Biol 149:1417-1429

Roberts EC, Wootton EC, Davidson K, Jeong HJ, Lowe CD,

Editorial responsibility: Ronald Kiene,

Mobile, Alabama, USA
Montagnes DJS (2011) Feeding in the dinoflagellate Oxyrrhis marina: linking behaviour with mechanisms. J Plankton Res 33:603-614

Schmoker C, Thor P, Hernández-León S, Hansen BW (2011) Feeding, growth and metabolism of the marine heterotrophic dinoflagellate Gyrodinium dominans. Aquat Microb Ecol 65:65-73

Schumann R, Munzert B, Wuensch JU, Spittler HP (1994) The feeding biology of Oxyrrhis marina Dujardin (Flagellata). Limnologica 24:29-34

Stoecker DK, Cucci TL, Hulburt EM, Yentsch CM (1986) Selective feeding by Balanion sp. (Ciliata: Balanidae) on phytoplankton that best supported its growth. J Exp Mar Biol Ecol 95:113-130

Strom SL (1991) Growth and grazing rates of the herbivorous dinoflagellate Gymnodinium sp. from the open subarctic Pacific Ocean. Mar Ecol Prog Ser 78:103-113

> Tillmann U, Alpermann TL, da Purificacao RC, Krock B, Cembella A (2009) Intra-population clonal variability in allelochemical potency of the toxigenic dinoflagellate Alexandrium tamarense. Harmful Algae 8:759-769

Tiselius P, Jonsson PR, Verity P (1993) A model evaluation of the impact of food patchiness on foraging strategy and predation risk in zooplankton. Bull Mar Sci 53:247-264

> Veloza AJ, Chu FL, Tang KW (2006) Trophic modification of essential fatty acids by heterotrophic protists and its effects on the fatty acid composition of the copepod Acartia tonsa. Mar Biol 148:779-788

Watts PC, Martin LE, Kimmance SA, Montagnes DJS, Lowe CD (2011) The distribution of Oxyrrhis marina: a global disperser or poorly characterized endemic? J Plankton Res 33:579-589

- Wood AM, Leatham T (1992) The species concept in phytoplankton ecology. J Phycol 28:723-729

> Zhang J, Li Y, Chen J (2010) Salinity tolerance and genetic diversity of the dinoflagellate Oxyrrhis marina. J Ocean Univ China 9:87-93

Submitted: September 10, 2012; Accepted: January 25, 2013 Proofs received from author(s): May 2, 2013 